\title{
Ao vivo direto da Rússia: a Copa do Mundo formatada para televisão
}

\author{
Live From Russia: The World Cup Shaped for TV
}

Fernando Vannier Borges

Universidade Lusófona de Humanidades e Tecnologias, Lisboa/Portugal Doutor em Ciências da Comunicação e Informação, Universidade Pantheon-Assas

fvsborges@outlook.com

\begin{abstract}
Resumo: Como megaevento esportivo, a Copa do Mundo tem uma grande capacidade de gerar atenção da Mídia. Entre os diferentes tipos de suporte, a televisão é o veículo mais relevante na difusão do futebol, tendo desenvolvido uma relação de simbiose com as organizações esportivas. Consciente da importância desse relacionamento, desde a década de 1960, a FIFA investe bastante da sua atenção na transmissão televisiva da Copa do Mundo, seu principal produto e sua maior fonte de recursos financeiros. Através da análise da versão de 2018 do Manual de Produção para TV da FIFA, pretendemos ver de que maneira a instituição contribui para a transformação da Copa do Mundo em um produto de televisão. Os resultados mostram que a FIFA passa a incorporar a lógica da mídia em suas ações e é responsável pela forma como a Copa do Mundo é transmitida para as emissoras oficiais.
\end{abstract}

PalaVRas-CHAVE: Copa do Mundo; FIFA; Transmissão televisiva; Midiatização.

ABSTRACT: As a mega-event, the FIFA World Cup has a great capacity to generate media attention. Among the different supports, television is the most important way to broadcast football. Also, football and media have developed a symbiotic relationship with the sportive organization. Aware of the importance of this relationship, FIFA has devoted a lot of attention to the broadcasting of the World Cup, which is FIFA's main product and source of revenue. Based on the analysis of the 2018 edition of the FIFA World Cup TV Production Handbook, our aim is to understand how FIFA transforms the World Cup into a TV product. Results show that FIFA adopts a media logic and is responsible for how the event is shaped to official broadcasters.

KEY-WORDS: World Cup; FIFA; TV Broadcast; Mediatization. 


\section{INTRODUÇÃO}

Ao lado dos Jogos Olímpicos, a Copa do Mundo é o evento esportivo mais importante do mundo. O seu impacto econômico e político, seu alcance internacional e a sua capacidade de movimentar o público - seja em audiências televisivas, seja no estádio ou na atração de turistas aos países sede - faz com que durante os 30 dias de competição seja difícil haver outro tema tão central na vida das pessoas, amantes ou não de futebol. A riqueza desse objeto de estudo ainda pode ser confirmada pela abordagem multidisciplinar ao assunto, o que justifica a elaboração de publicações "Sobre Copas do Mundo...”.

Eventos com grande capacidade de atração do público passaram a ser conhecidos como megaeventos. Maurice Roche ${ }^{1}$ foi um dos pioneiros na definição e estudo desses eventos que ganharam muita atenção nos últimos anos. ${ }^{2}$ Com a intenção de clarificar a definição dos megaeventos, Müller ${ }^{3}$ propôs critérios com base em alcance, midiatização, custos e transformação urbana, para elaborar uma escala de tamanho desses eventos. 0 autor propõe uma classificação em "giga", "mega" e "major", e a sua conclusão aponta para a tendência de que os Jogos Olímpicos e as Copas do Mundo passem a se tornar "gigaeventos".

A Copa do Mundo tem uma forte presença cultural e social nas nossas vidas. Os ciclos de quatro anos de intervalo são marcados por prolongados períodos de classificação, preparação e construção do evento, assim como toda a gama de eventos FIFA (Copa do Mundo Feminina, Mundiais de categorias jovens, eventos de premiação anual), de modo que se constrói uma grande expectativa para a Copa. ${ }^{4}$

Um dos elementos centrais aos megaeventos é a sua capacidade de atrair a atenção do público e da mídia. Copas do Mundo são uma grande fonte de narrativas - dramáticas, épicas e até mesmo cômicas - que são exploradas pela mídia, são recontadas pelas pessoas e revividas na memória individual e coletiva

\footnotetext{
${ }^{1}$ ROCHE. Mega-events and modernity, 2000; ROCHE. Mega-events, time and modernity, 2003, p. 99-126.

${ }^{2}$ GRUNEAU; HORNE. Mega-Events and globalization, 2016, p. 1-28; HORNE; MANZENREITER. An introduction to the sociology of sports mega-events, 2006, p. 1-24; MARIVOET. Euro 2004 ${ }^{T M}, 2006$.

${ }^{3}$ MÜLLER. What makes an event a mega-event?, 2015, p. 627-642.

${ }^{4}$ HAYNES; BOYLE. The FIFA World Cup, 2017, p. 86.
} 
de um país, mostrando a importância cultural e simbólica desses eventos. Ao longo da história, diferentes suportes tiveram o seu papel na cobertura da Copa do Mundo, mas atualmente é a televisão e os meios digitais que recebem maior destaque na transmissão dos jogos.

Os megaeventos apresentam uma capacidade de atração superior aos eventos esportivos do cotidiano, fazendo com que haja uma relação ainda mais estreita com o público ${ }^{5}$ do que a já habitual proximidade. ${ }^{6}$

Dentro dos diferentes suportes, a televisão merece um destaque especial: o relacionamento entre a TV e o futebol é fundamental para a sua construção enquanto esporte-espetáculo, assim como a expansão global da FIFA e da Copa do Mundo foi beneficiada pela parceria com a televisão. Através da análise da versão de 2018 do Manual de Produção para TV da FIFA, pretendemos encontrar evidências para analisar a formatação da Copa do Mundo em um produto televisivo e as transformações da FIFA, incorporando a lógica midiática à sua organização.

\section{TELEVISÃO E FUTEBOL}

Para Helland, ${ }^{7}$ as noções de simbiose e parasitismo são essenciais na análise da relação entre o mundo esportivo e a TV. A simbiose descreve a coabitação de dois organismos diferentes a partir da qual ambos se beneficiam, porém, no caso do parasitismo, apenas uma das partes envolvida sai beneficiada. Outra forma de ver o relacionamento é através da metáfora do casamento. A união matrimonial pode representar um casamento de conveniência entre ambos ou um relacionamento que torna cada uma das partes mais fortes através do "amor". Outras metáforas alternativas já foram usadas, e cada uma delas traz para a análise um tipo de relação e a sua respectiva balança de poder. Para alguns, a preocupação a respeito

\footnotetext{
${ }^{5}$ BILLINGS; WENNER. The curious case of the megasporting event, 2017, p. 3-18.

${ }^{6}$ ROWE. Sport, culture and the media, 2004; WENNER. Media, sports, and society, 1989, p. 13-48.

${ }^{7}$ HELLAND. Changing sports, changing media, 2007, p. 105-119.
} 
dessa ligação é o risco de que a televisão esteja colonizando o esporte, isto é, os seus valores estão sendo perdidos para a os valores televisivos. ${ }^{8}$

A relação entre esporte e televisão e a consequente construção do futebol como um produto televisivo é o resultado de um processo histórico. A partir de elementos usados em outros tipos de mídia, como rádio, filme e fotos, a TV construiu a sua narrativa e desenvolveu o seu papel na difusão do futebol enquanto conteúdo televisivo. 0 esporte cresceu enquanto forma de discurso graças à popularização de jornais e revistas que tratavam do assunto, permitindo que se tornasse uma prática corrente falar, antecipar, comentar, atacar e defender as ações de atletas e clubes; assim como o rádio aproximou as pessoas ao acontecimento esportivo que, por sua vez, ganhou um rosto e emoção através das imagens fotográficas e fílmicas.

Portanto, antes da chegada da TV, o futebol já era um produto muito próximo à mídia, mas depois que começou a aparecer na "telinha", a experiencia do público mudou completamente, aproximando-se ainda mais da sensação de viver o acontecimento, bem como o apelo ao seu envolvimento. ${ }^{9}$ A televisão teve papel central na construção do espetáculo-esportivo, de tal modo que hoje é difícil separar o futebol profissional de sua parceria com a mídia.

A força da televisão, graças à difusão ao vivo, reside na sua capacidade de moldar o esporte em um formato televisivo. 0 futebol é um produto particularmente adaptado à lógica do fluxo da televisão, uma vez que apresenta as seguintes características: permite uma combinação de elementos previsíveis e de incertezas; supera o antagonismo entre repetição e diferenciação; e também é um conteúdo programável, admitindo ser exibido ao vivo ou em diferido. Se forem detentoras dos direitos de transmissão, as televisões podem ter ainda mais poder sobre a agenda dos jogos, definindo os dias e horários de início das partidas de acordo com a sua conveniência. Além disso, o tempo de jogo definido (dois tempos de 45 minutos, com intervalo de 15 minutos) permite um controle mais eficiente

\footnotetext{
${ }^{8}$ ROWE. The global love-match: sport and television, 1996, p. 565-582.

${ }^{9}$ ROWE. The global love-match: sport and television, 1996, p. 568.
} 
da grade de programação, por parte das emissoras de televisão, que também podem inserir anúncios publicitários no intervalo ou nos tempos mortos do jogo.

Primeiramente, a emissão de um jogo passa por uma implementação de um dispositivo técnico e cênico, que é reforçado por ligações espaciais - os jornalistas que acompanham o jogo dentro do campo, os comentários no estúdio e os espectadores em casa - e simbólicas. A televisão tenta controlar o tempo do acontecimento, por vezes o dilatando através de programas antes e após as partidas, e outras vezes o comprimindo através da aceleração ou supressão de certos momentos mais entediantes para a audiência. ${ }^{10}$

A transmissão de eventos esportivos foi relevante num âmbito mais geral, pois teve um papel importante na construção da linguagem televisiva. No processo de elaboração da emissão esportiva, o objetivo das empresas de comunicação era desenvolver a tecnologia de transmissão ao vivo para fazer o espetáculo mais real. Elemento fundamental do espetáculo esportivo na televisão, o ao vivo teve também outras funções como a construção da reputação, notoriedade e credibilidade da televisão, tornando-se uma marca de sua identidade. ${ }^{11}$

A transmissão via satélite, a partir dos anos 1960, multiplicou as emissões esportivas na televisão. 0 aumento da concorrência entre canais modificou o objetivo das transmissões, deixando de ser uma mera reprodução da experiência visual do estádio na TV, para tentar ser a melhor maneira de visualização de um espetáculo concebido por e para esse suporte midiático. ${ }^{12}$ A reconstrução do visível passa a tornar o futebol mais telegênico; rentabilizar os grandes investimentos feitos com os direitos de transmissão, ajustando os eventos mais importantes para horários de maior audiência; adaptar as emissões aos anúncios publicitários; organizar os eventos de modo a dar visibilidade aos parceiros publicitários; multiplicar os pontos de vista através da proliferação do número de câmeras; criar e implementar estratégias de marketing para tais eventos; e construir um discurso que valorize a espetacularização. ${ }^{13}$

\footnotetext{
${ }^{10}$ PAPA. Quand le sport nous parle de la télévision, 2000, p. 420.

${ }^{11}$ WILLE. Une diachronie du spectacle sportif télévisé, 2000, p. 434.

12 WILLE. Une diachronie du spectacle sportif télévisé, 2000, p. 437.

${ }^{13}$ WILLE. Une diachronie du spectacle sportif télévisé, 2000, p. 440.
} 
No início da relação entre o futebol e a TV, os dois eram vistos como competidores. A economia do esporte se baseava no princípio de que um grande número de pessoas sairia de casa para ir ao estádio e pagar pelos bilhetes para ver jogadores profissionais em embates pela vitória. A bilheteria e os gastos complementares nos recintos eram a fundação do sucesso financeiro de um clube, e assim não era difícil imaginar os motivos que faziam temer a oferta de um aparelho que representava a antítese de ir ao estádio. Hoje, a relação do torcedor com o espetáculo mudou por influência dos meios de comunicação, mas no início a experiência televisiva era vista como solitária e que não oferecia o engajamento necessário com o clube, tornando-se assim uma experiência de menor valor - tal como ver a reprodução de um quadro por oposição ao seu original. 0 medo dos clubes era o de perder dinheiro, na medida em que, com a transmissão televisiva, o público presente nos estádios diminuiria, e o de que estes perdessem a sua atmosfera vibrante.

Com o tempo percebeu-se que as receitas com os direitos de transmissão e a publicidade poderia se equiparar ao das bilheterias, e o paradigma da relação entre a TV e o futebol mudou, deixando de ser concorrência, para trabalharem em conjunto. A maior contribuição da TV foi a possibilidade de alcançar pessoas que já não iriam ao estádio, torcedores que não tinham a capacidade de se locomover para acompanhar seus clubes poderiam ver os jogos pela TV. ${ }^{14}$ Os jogos passaram a poder ser trazidos de todos os cantos dos países e do mundo, e foi a partir daí que se deu o crescimento do futebol, e da Copa do Mundo, enquanto produto global.

\section{A Fifa E A TELEVISÃo}

Haynes e Boyle ${ }^{15}$ apresentaram uma historiografia da cobertura televisiva da Copa do Mundo para entender como as novas tecnologias são acomodadas nas estruturas institucionais de organizações esportivas e de emissoras de televisão para fazer da Copa um evento televisivo. Segundo os autores, o processo está dividido em três fases: “1) 1954-1962: Fase de iniciação do futebol internacional

\footnotetext{
${ }^{14}$ ROWE. The global love-match: sport and television, p. 570.

${ }^{15}$ HAYNES; BOYLE. The FIFA World Cup, p. 86.
} 
na TV; 2) 1966-1998: A disputa pelo controle do espetáculo; 3) 2002-presente: A incerteza do processo de convergência e a mídia divergente". ${ }^{16}$ Haynes e Boyle enfatizam que há sobreposições e continuidades ao longo desses períodos, mas a classificação se faz necessária para diferenciar algumas épocas em relação aos seus aspectos tecnológicos e culturais.

A criação e a evolução da Copa do Mundo acontece em paralelo ao desenvolvimento dos meios de comunicação modernos. Durante as três primeiras edições (1930, 1934 e 1938), o rádio e a imprensa escrita tiveram o protagonismo, embora todas tenham sido filmadas e a Copa de 1938 tenha recebido bastante destaque nos cinejornais da época. Em 1950, as transmissões televisivas já haviam avançado o suficiente, mas no Brasil ainda não foi possível a implementação, de modo que ainda predominou o rádio como forma de difusão do evento para o mundo. ${ }^{17}$

A Copa de 1954, na Suíça, foi a primeira a ser transmitida pela TV. Emissoras europeias formaram um consórcio internacional (EBU - European Broadcast Union), e nesse período pós-guerra, o futebol representava simbolicamente a universalidade e a superação de barreiras nacionais. Cada emissora nacional - muitas delas em operação há menos de um ano, contavam com a BBC para empréstimo de materiais e expertise - tinha o próprio narrador para as mesmas imagens, fosse no estádio ou em um estúdio isolado. A técnica de separar o som do ambiente (estádio) dos comentários (estúdio) foi usada pela primeira vez na cerimônia de coroação da Rainha Elizabeth II, em 1953. Isso representou um padrão de emissão de eventos esportivos internacionais com a combinação de feeds unilaterais e multilaterais, permitindo que cada emissora nacional se apropriasse do sinal internacional para emissões locais. Ainda hoje, essa forma de transmissão, que ficou conhecida como eurolinks, se mantém um importante mecanismo de identificação linguística e cultural para eventos globais. ${ }^{18}$

\footnotetext{
${ }^{16}$ Original em inglês: 1) 1954-1962: The initiating phase of international television football; 2) 1966-1998: The hegemonic struggle for control of the media spectacle; 3) 2002-present: The uncertain age of convergent processes and divergent media.

${ }^{17}$ HAYNES; BOYLE. The FIFA World Cup, 2017, p. 88.

${ }^{18}$ HAYNES; BOYLE. The FIFA World Cup, 2017, p. 88.
} 
Em 1958, os eurolinks continuavam a funcionar e foram se aprofundando as relações simbióticas entre as instituições esportivas - FIFA e federações nacionais - e as empresas de mídia, na medida em que os estádios iam sendo adaptados para receber as equipes de TV. Pela primeira vez, uma empresa (EBU) pagou pelos direitos de transmissão do evento. Durante a Copa da Suécia, muitos jogos aconteciam em horários semelhantes, motivando a BBC a entrar com um pedido, sem sucesso, para que a FIFA reorganizasse o calendário. ${ }^{19}$ Algo que viria a mudar no futuro.

Com a realização da Copa de 1962, no Chile, a transmissão ao vivo dos jogos era impossível para a Europa. Assim, a BBC colocou em prática um meticuloso plano para transportar o filme dos jogos a serem exibidos ao público 48 horas após o final do jogo. 0 material seria transportado de Santiago para Lima, a seguir para o Panamá e de lá para Miami e depois para NYC. Por fim, pegaria o primeiro vôo para Londres. Os investimentos feitos pela BBC dão a noção da importância dada ao evento. ${ }^{20}$

A partir de 1962, a FIFA passou a centralizar a venda dos direitos de transmissão da Copa. Entre a primeira e a segunda venda já houve uma grande inflação: a EBU pagou 75 mil dólares em 1962 e 800 mil em 1966. ${ }^{21}$ Com o tempo e a competição no mercado de telecomunicações, essa foi uma tendência que foi aumentando de maneira exponencial (ver tabela 1). Por um lado, a venda dos direitos de transmissão se tornou a principal, e volumosa, fonte de renda da FIFA (ver figura 1); mas, por outro lado, com mais investimento por parte das emissoras, também veio mais intervenção na organização e agenda dos jogos de acordo com a demanda da TV.

\begin{tabular}{|l|l|}
\hline Data (País sede) & Total \\
\hline 1978 (Argentina) & 34 \\
\hline 1982 (Espanha) & 55 \\
\hline 1986 (México) & 70 \\
\hline 1990 (Itália) & 135 \\
\hline 1994 (EUA) & 150 \\
\hline 1998 (França) & 350 \\
\hline 2002 (Japão e Coréia do Sul) & 1200 \\
\hline 2006 (Alemanha) & 1400 \\
\hline
\end{tabular}

\footnotetext{
${ }^{19}$ HAYNES; BOYLE. The FIFA World Cup, 2017, p. 89.

20 HAYNES; BOYLE. The FIFA World Cup, 2017, p. 89.

${ }^{21}$ HAYNES; BOYLE. The FIFA World Cup, 2017, p. 90.
} 


\begin{tabular}{|l|l|}
\hline 2010 (África do Sul) & 2100 \\
\hline 2014 (Brasil) & 2500 \\
\hline 2018 (Rússia) & 3000 \\
\hline
\end{tabular}

Legenda: valores de vendas dos direitos de transmissão da Copa do Mundo (em milhões de dólares).

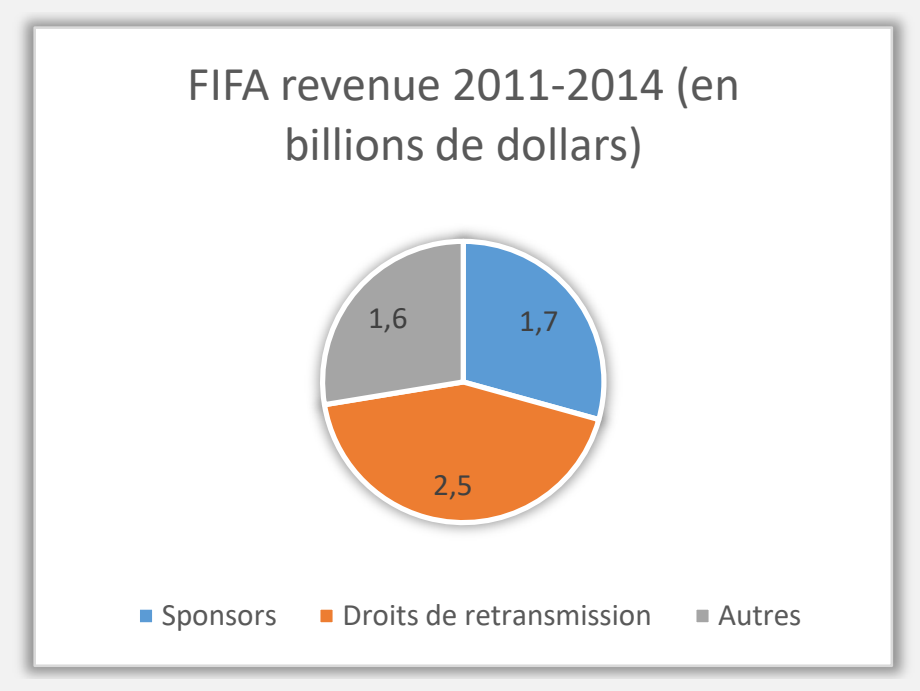

A cobertura da Copa de 1966, na Inglaterra, representou um ponto de viragem no processo de transmissão do evento. Pela primeira vez a Copa foi transmitida para a América Latina (México), assim como introduziu-se o replay e a câmera lenta. A Copa passou a ser um grande momento para introduzir inovações tecnológicas no mercado de TV. Em 1966, a transmissão a cores já seria possível, mas foi negada pois o governo britânico considerou que os produtores nacionais de aparelhos não estavam aptos a competir com os congêneres japoneses e americanos. $^{22}$ Até hoje, as Copas do Mundo são importantes marcos na implementação de novas tecnologias, seja em termos narrativos (exemplificado pelas transformação das emissões nos estúdios) ou em termos tecnológicos (exemplificados pela introdução do HD, 3D, 4K, segunda tela).

Ao longo dos anos 1980 e 1990, os avanços tecnológicos caminharam no sentido da utilização de câmeras e no uso de gráficos e informações de análise durante os jogos. Nesse período, a ênfase na retórica tecnológica deu lugar a uma

${ }^{22}$ HAYNES; BOYLE. The FIFA World Cup, 2017, p. 90. 
tentativa de aumentar os elementos dramáticos e de entretenimento do espetáculo esportivo, de modo a incrementar a experiência da audiência, devido à competição entre diferentes emissoras de TV, no mercado de cada país. ${ }^{23}$

O novo período do televisionamento da Copa do Mundo começa na era da convergência. Os direitos de TV para 2002 e 2006 foram negociados internacionalmente pela ISL-Kirch Media Group e abriu portas para negócios individuais por país e separados por canais abertos e fechados. ${ }^{24}$ Essas mudanças foram de encontro às alterações no mercado de telecomunicações: liberalização e concorrência entre diferentes atores; revolução digital; aumento da oferta de conteúdos relacionados ao futebol.

Para Haynes e Boyle, ${ }^{25}$ o futebol tem um importante papel no desenvolvimento de novas formas de transmissão e consumo de mídia porque há um grande contingente do público consumidor de futebol que é composto por homens, jovens e "early adopters" de tecnologia - um dos segmentos de mercado mais atraentes para as empresas. Contudo, os avanços tecnológicos e a oferta de conteúdos digitais ainda não foi o suficiente para tirar da TV o protagonismo, pois esse ainda é o suporte preferido na hora de ver jogos durante a Copa do Mundo.

\section{A PROdUÇão da CoPA do Mundo PARA A TELEVISÃo}

Competições internacionais, como a Copa do Mundo, e outros torneios sob a chancela da FIFA são acessíveis à maior parte do público através de diferentes suportes midiáticos, mas principalmente pela televisão. Em nome da promoção do espetáculo esportivo e das suas receitas, a FIFA precisa estabelecer boas relações com as empresas de comunicação para que os seus torneios sejam transmitidos e estejam em conformidade com as suas regras e padrão de qualidade. Para isso, em 2007, a FIFA centralizou internamente todos os serviços de televisão em um departamento: FIFA TV Division.

\footnotetext{
${ }^{23}$ HAYNES; BOYLE. The FIFA World Cup, 2017, p. 91.

${ }^{24}$ HAYNES; BOYLE. The FIFA World Cup, 2017, p. 92.

${ }^{25}$ HAYNES; BOYLE. The FIFA World Cup, 2017, p. 93.
} 
Esse setor da FIFA é responsável pela venda de direitos de transmissão, produção e gestão de um arquivo de imagens (FIFA Filmes), prestação de serviços a empresas detentoras de direitos de transmissão e operação de eventos. Segundo a própria FIFA: ${ }^{26}$

FIFA's TV Division is structured to meet the demands of 21st century broadcasting, technology and media environments. With rapidly increasing media convergence and the subsequent proliferation of content, it is increasingly important for rights holders, advertisers, sponsors and other commercial entities to stand out from the crowd. FIFA, through the FIFA World $\mathrm{Cup}^{\mathrm{TM}}$ and its portfolio of other events, delivers standard-setting quality content to broadcasters around the globe.

Para a Copa de 2018, na Rússia, a responsabilidade da FIFA TV era conseguir a maior audiência possível para o evento e oferecer a melhor experiência para quem estivesse assistindo aos jogos. A FIFA TV está dividida em quatro áreas: Vendas e Distribuição; FIFA Filmes \& Produtos; Serviços de emissão; Produção para emissoras oficiais. 0 setor de Vendas e Distribuição é responsável pela negociação de todas as competições FIFA para TV, internet, mídias móveis e rádio com as empresas de comunicação, sendo portanto peça essencial na aquisição de receitas da organização. FIFA Filmes \& Produtos produz conteúdos a serem usados pelas emissoras de televisão e plataformas online, gere e comercializa o arquivo de imagens da FIFA, gere o canal da FIFA no Youtube e produz conteúdos promocionais e documentais nos locais dos eventos. Os Serviços de emissão são o ponto de contato entre a FIFA e os detentores de direitos de transmissão (MRL, da sigla em inglês - Media Rights Licensees), responsáveis pela supervisão dos prestadores de serviço de transmissão (por parte da FBST - FIFA Broadcaster Servicing Team). A equipe de Produção para emissoras oficiais (Host Broadcast Production) supervisiona o material enviado para todas as emissoras com direitos de transmissão dos eventos FIFA, garantindo a qualidade de seus serviços. A FIFA nomeou a HBS (Host Broadcast Services) como responsável pelo serviço prestado na Rússia.

${ }^{26}$ FIFA. Who we are: https://bit.ly/2Mzbh6H. 
A HBS foi criada, em 1999, para produzir os sinais de TV e Rádio das Copas de 2002 e 2006. Com base nessa experiência, a empresa passou a ser responsável pelos mundiais de futebol subsequentes e também pôde expandir o seu portfólio de eventos, incluindo os jogos pan-asiáticos e a Liga Francesa de Futebol. Com sede na Suíça e escritórios em Paris, a HBS é uma empresa "sanfona" que conta com cerca de 100 pessoas em média, mas que pode atingir cerca de 3000 funcionários durante a cobertura de grandes eventos. A HBS é subsidiária da Infront Sports \& Media. A FBST é uma entidade da Infront Sports \& Media que presta serviços à FIFA. Dentre eles estão: operações nas sedes FIFA; implementação das orientações da FIFA; acreditação das MRLs. No geral, a FBST oferece à FIFA um serviço que garante a ligação diária com todas as empresas detentoras de direitos para todos os assuntos que extrapolem a área da HBS.

Ao centralizar a produção dos jogos, a FIFA fica responsável pela geração de imagens a serem enviadas para as emissoras oficiais a partir dos estádios. Como parte desse trabalho, ela desenvolve um manual de produção ${ }^{27}$ com toda a informação básica para a emissão da Copa do Mundo, e esse documento é distribuído a todas as emissoras oficiais. Como parte desse projeto de pesquisa, foi possível ter o acesso aos manuais de 2010, 2014 e 2018. Uma análise comparativa entre eles permite apontar algumas características gerais: longo documento com cerca de 200 páginas, nas quais descreve-se e são informadas várias das rotinas que envolvem o trabalho de cobertura midiática da Copa do Mundo, explicando a organização da FIFA, do Comitê Organizador Local, as características de cada cidade sede, os estádios, as áreas de trabalhos para quem faz a cobertura e os aspectos técnicos de produção.

No manual referente à Copa do Mundo de 2018, o capítulo três descreve o plano de produção da FIFA para a transmissão dos jogos. 0 plano de produção estabelece orientações específicas para a cobertura dos 64 jogos da Copa, incluindo elementos narrativos, técnicos e gráficos que garantam o mesmo padrão para todos os jogos. Pela primeira vez nas Copas do Mundo, todos os jogos do evento foram produzidos em UHD (Ultra High Definition) e HDR (High Dynamic Range),

\footnotetext{
${ }^{27}$ FIFA. FIFA World Cup TV Production Handbook, 2018.
} 
disponibilizando formatos de vídeo em 1080i, 1080p ou UHD/HDR. Ainda no campo da inovação, a produção de imagens na Rússia contou com a possibilidade de transmitir jogos em realidade virtual (VR) ao vivo e em vídeo 360 graus sob demanda.

A produção é dividida entre a emissão ao vivo e o conteúdo gravado. 0 primeiro diz respeito ao que gira em torno da transmissão de cada jogo da Copa do Mundo, em termos de áudio e vídeo, tendo uma função de transformar o espetáculo do estádio em televisivo. A outra parte da produção tem um caráter mais informativo, dado que os conteúdos gravados cobrem as equipes que estão no torneio, curiosidades e estatísticas sobre atletas, entrevistas coletivas e o acompanhamento antes e depois dos jogos.

A emissão ao vivo é feita por oito equipes. Cada unidade de trabalho é coordenada por um diretor de televisão com larga experiência na cobertura de eventos FIFA e UEFA. A liderança das oito equipes é toda masculina e europeia, sendo três franceses, três britânicos e dois alemães. Cada estádio da Copa conta com 39 câmeras, sendo 37 para a transmissão dos jogos e duas câmeras adicionais que captam imagens de torcedores dentro e fora do estádio para serem usadas em momentos de transição dos planos. Além das imagens, a FIFA fornece a narração em inglês dos jogos.

Todo o conteúdo produzido pela FIFA chega às emissoras através de feeds multilaterais. Essa é a forma mais eficiente de enviar grandes quantidades de conteúdo às emissoras oficiais da Copa, e para muitas delas é a principal fonte de material. Os feeds oferecidos pela FIFA estão divididos em dois grupos: padrão e isolados. Os dois grupos são compostos por 10 sinais cada. Os feeds padrão são: ESF (Extended Stadium Feed); CSF (Clean Stadium Feed); EBIF Show; Permanent Highlights; Tactical and Additional Content Feed; Team A \& B Feeds; PlayerCam A \& B Feeds; Clips compilation Channel - Action; e Clips compilation Channel Emotion; UHD/HDR dirty. Os feeds isolados são: Camera 1; Camera 16m High L; Camera 16m High R; Camera High Behind Goal Right; Reverse Centre High; Beauty; Cable Cam; Aerial (Helicóptero); UHD/HDR Camera 1; e UHD/HDR Tactical. ${ }^{28}$ Cada

\footnotetext{
${ }^{28}$ Por se tratar de termos técnicos, que entram no jargão profissional dessa forma, decidiu-se pela manutenção do termo original em inglês.
} 
feed pode ter duração própria, indo desde duas horas antes do apito inicial, até uma hora após o fim das partidas. Para efeitos desse trabalho, vamos nos deter a uma breve descrição dos feeds principais.

O ESF é o feed principal para as emissoras oficiais. É um sinal ininterrupto que cobre todo o jogo e permite que as emissoras tenham a transmissão de uma partida, com os gráficos em inglês (placar, escalação, relógio podendo ser em outra língua consoante à contratação do serviço), podendo ser acrescentados conteúdos de produção própria e a narração de uma equipe no estádio ou em um estúdio remoto. Esse é um sinal recomendado para emissoras com presença no país da Copa - seja no estádio ou apenas com produção de estúdios. O CSF complementa o ESF pois é o sinal limpo, sem gráficos, para a produção de clipes. Ainda esteve disponível uma versão do ESF em alta definição (UHD/HDR dirty) que fornecia imagens com melhor qualidade. Para emissoras de menor tamanho e sem produção própria, o feed EBIF show é o complemento ao ESF, pois antes dos jogos, nos intervalos e após o apito final, ele oferece clipes, gráficos com informação, estatísticas e outros conteúdos que estão prontos a serem usados, sem a necessidade de edição suplementar.

O Team A \& B Feed se destina a acompanhar, separadamente, as duas seleções envolvidas em um jogo. Ao longo de sua duração inclui a chegada no estádio, aquecimento, banco de reservas, movimentação de substitutos e entrevistas. De maneira complementar, o feed específico para jogadores vai seguir três atletas pré-selecionados para acompanhar durante 15 minutos de cada tempo de jogo. Há ainda o Tactical Feed que mostra o campo inteiro, de modo a permitir a análise tática da partida.

Os feeds de compilação de clipes são gerados a partir de imagens que aconteceram pouco tempo antes, dividindo-se entre um canal de ação e outro de emoção. 0 primeiro oferece, em ordem cronológica, os principais lances dos jogos, com maior detalhe e variados ângulos de câmera, permitindo uma imersão na ação dos jogos. 0 segundo oferece imagens das arquibancadas, mostrando os torcedores e suas reações, para ilustrar e refletir a experiência no estádio. Outro feed com clipes é o Permanent Highlights. Ele oferece os melhores momentos de cada jogo 
em modo contínuo, servindo para um acesso rápido aos resumos dos jogos e para fácil utilização em plataformas digitais.

O conteúdo gravado foi produzido por 40 equipes, sendo 32 para acompanhar cada seleção, para filmar treinos e entrevistas, e oito para contar histórias das 11 sedes. Todo o conteúdo foi disponibilizado no servidor FIFA Max, onde também estarão disponíveis vídeos promocionais de jogos e programas já editados, prontos para serem exibidos, como por exemplo o "Preview Show", com a antevisão dos jogos, e o "Daily Match Highlights Show", com o resumo do dia de competição. Por fim, ainda é preciso destacar um serviço de informação oferecido pela FIFA que envia, por correio eletrônico, aos interessados, estatísticas e dados históricos sobre cada um dos confrontos, para facilitar que narradores e comentaristas possam acrescentar valor às suas emissões. As informações são enviadas maioritariamente antes dos jogos, mas também podem ser enviadas durante os jogos para enriquecer momentos marcantes da partida.

\section{A MidiatizaÇão da CoPa do Mundo}

Com base na teoria de Foucault, Rowe ${ }^{29}$ apresenta diferentes formas e efeitos do poder, sem que esse seja um conceito necessariamente negativo. Podendo tratar de efeitos rápidos ou cumulativos no processo de transformação, Rowe analisa a questão através das seguintes manifestações de poder: a) ao nível institucional como a mídia e as organizações esportivas se uniram de modo que uma possa ter dominado a outra e a extensão da transformação em ambas; b) a nível simbólico como os textos produzidos pelos media são produzidos e interpretados, de acordo com as diferentes condições de trabalho e sociais; c) ao nível relacional - as amplas ramificações sociais e culturais do desenvolvimento de um sistema de produção global de esporte pelos meios de comunicação, e como os mitos e símbolos criados contribuem para a forma de estar no mundo.

\footnotetext{
${ }^{29}$ ROWE. The global love-match: sport and television, 1996, p. 34.
} 
No presente artigo, a nossa preocupação é no nível institucional. Em especial, é preciso fazer a análise de como a FIFA, em parceria com a Mídia, transforma a Copa do Mundo em um produto de televisão. Para isso, é importante entender o processo de midiatização das organizações esportivas. ${ }^{30}$ Esse conceito foi desenvolvido para capturar as consequências da utilização dos diferentes tipos de mídia na vida cotidiana. ${ }^{31} \mathrm{~A}$ atenção a esse fenômeno veio na medida em que a mídia passou a se tornar onipresente nas sociedades capitalistas modernas. Ao final da primeira década do século XXI, se espalhou e consolidou o acesso a Internet de alta velocidade, a democratização de smartphones e o surgimento de novas formas de comunicação em plataformas digitais.

Entre as diferentes correntes da teoria de midiatização, na análise da FIFA e das transformações da Copa do Mundo, a abordagem que mais se aplica é a institucionalista. Essa linha de pesquisa estuda a maneira como várias instituições de diferentes campos sociais passam a institucionalizar práticas e comportamentos sob a "lógica da mídia".32 Apesar de cada tipo de suporte e cada meio de comunicação apresentar sua própria forma de funcionar, a noção de lógica da mídia cobre as regras que determinam o comportamento geral. 0 conceito foi proposto pela primeira vez por David Altheide e Robert Snow, ${ }^{33}$ sendo, posteriormente, desenvolvido pelo primeiro, ao esclarecer que a lógica da mídia se expressa no processo de criação da mensagem, incluindo ritmos, gramática e formato. Esses são traços especialmente relevantes pois determinam como se produzir e identificar informação. ${ }^{34}$

Ao criar o departamento da FIFA TV e centralizar a produção audiovisual da Copa do Mundo, a FIFA institucionaliza as lógicas da mídia. A transformação dos jogos em espetáculo televisivo obedece aos ritmos, gramáticas e formatos que as emissoras de televisão construíram ao longo do tempo. Mais do que responsável pela montagem do espetáculo futebolístico, a FIFA vai além na sua atuação midiática, na medida em que também produz conteúdos informativos.

\footnotetext{
${ }^{30}$ FRANDSEN. Sports organizations in a new wave of mediatization, 2016, p. 385-400.

${ }^{31}$ COULDRY; HEPP. Conceptualizing mediatization, 2013, p. 191-202.

32 HJARVARD. The mediatization of society, 2008, p. 105-134.

33 ALTHEIDE; SNOW. Media logic, 1979.

${ }^{34}$ ALTHEIDE. Media logic and political communication, 2004, p. 293-296.
} 
Enquanto gênero televisivo, o esporte não tem uma posição claramente demarcada. Tendo como material primário acontecimentos que são transmitidos ao vivo, na maior parte sem nenhum tipo de edição, o futebol pode ser interpretado como atualidade, muito próximo na noção de informação e reportagem. Mas a estruturação em programas, a forma como se dirige ao público e a sua representação estruturam o conteúdo como entretenimento.

Para Whannel, ${ }^{35}$ ao invés de binária, a posição do esporte na televisão está no centro de um triângulo cujos vértices são a informação, o entretenimento e o drama. A performance atlética transmitida ao vivo carrega uma grande dose de realismo e atualidade, mas na tentativa de aprimorar a experiência de quem assiste, o espetáculo do estádio é transformado em televisivo através do uso de câmeras lentas, close-ups e repetições. Mais ainda, ao tentar captar e reter a audiência, os produtores de televisão podem oferecer elementos e surpreender os espectadores de formas que não seriam possíveis no estádio, criando um novo tipo de drama. É preciso pensar na transformação do futebol em conteúdo de televisão como o resultado de um processo rico em tensões por todos os lados.

Para um maior entendimento da construção do espetáculo esportivo televisivo, seria necessário uma análise de conteúdo que permitisse um estudo sobre as características estéticas e narrativas do futebol na televisão. Apesar de relevante, esse não foi o objetivo principal desse trabalho. Contudo, o manual de produção para TV da FIFA se mostrou uma rica fonte de pesquisa, que poderá ser mais explorado.

Embora haja debate sobre a capacidade da televisão em substituir a emoção de ver o jogo pessoalmente, é inegável que a experiência televisiva é completamente diferente do estádio. A popularização da transmissão dos jogos pela TV produz novas expectativas e frustrações por parte do público: o desejo de ver replays e a decepção de ficar preso a um determinado ponto de vista escolhido por outra pessoa, assim como a perda de experiência e emoções únicas ao estádio em troca de conforto e enriquecimento da forma de ver o jogo. ${ }^{36}$

\footnotetext{
${ }^{35}$ WHANNEL. Fields in vision: television sport and cultural transformation, 1992, p. 63.

${ }^{36}$ WHANNEL. Fields in vision: television sport and cultural transformation, 1992, p. 92.
} 
Organizações esportivas e empresas de comunicação fazem ajustes às suas ofertas na tentativa de saciar os desejos do público. Imagens em alta definição, áudio ambiente, câmeras dentro do túnel e do vestiário têm por objetivo colocar o telespectador dentro do estádio. Da mesma forma, os estádios passaram a incorporar em sua arquitetura grandes telas para exibir a repetição de lances e outras formas de entretenimento durante o jogo e seus intervalos. Em jogos de Copa do Mundo essa transformação dos estádios fica evidente, pois telões fazem parte do "padrão-FIFA".

Preocupada com a dicotomia entre estádio e TV, a FIFA também encontrou a sua própria solução para a questão. Reconhecendo que há uma limitação de lugares disponíveis nos estádios durante as Copas do Mundo, em 2006, a FIFA criou espaços de exibição dos jogos em telões gigantes: a FIFA Fun Fest. Nesses espaços, a FIFA promete oferecer a experiência da Copa do Mundo para quem não pode ir aos estádios, unindo o melhor dos dois mundos. ${ }^{37}$

\section{CONSIDERAÇõES FINAIS}

Desde a sua criação, em 1930, a Copa do Mundo é o evento principal da FIFA. A partir das décadas de 1960 e 1970, é possível notar um projeto institucional de aumentar a Copa, que se refletiu no número de participantes, nos contratos de patrocínio, no alcance global e na exposição midiática. Junto com a importância cultural e simbólica do futebol para a maior parte dos países do mundo e a construção de suas identidades, a Copa do Mundo - ao lado das Olimpíadas - é o evento internacional mais importante do planeta.

Reconhecendo a importância comercial da televisão para a Copa do Mundo, desde cedo a FIFA investiu na parceria com as emissoras de televisão. Com a revolução digital, tornou-se mais fácil investir em comunicação e houve uma abertura ao mercado midiático. No novo século, a FIFA decidiu centralizar as responsabilidades de mídia e criou o seu departamento interno de televisão. A

\footnotetext{
${ }^{37}$ BORGES. O papel da FIFA Fan Fest ${ }^{\mathrm{TM}}$ na Copa do Mundo da África do Sul, 2013, p. 201-230.
} 
centralização garante à FIFA que haja um padrão de qualidade transversal a todas as emissoras oficiais e uma exploração global do seu principal produto.

O avanço tecnológico e o crescimento comercial da Copa do Mundo permitiram que a FIFA diversificasse as possibilidades de exploração. Não só a FIFA criou as Fan Fests, mas também tem investido nos seus próprios canais página oficial e Youtube - e redes sociais. A presença da FIFA em múltiplas plataformas e a análise de como se organiza a convergência da Copa do Mundo em termos midiáticos é um dos elementos que precisarão ser desenvolvidos no futuro.

No presente trabalho, a análise do manual de produção mostra a preocupação da FIFA em explorar a Copa do Mundo em suas possibilidades audiovisuais. Fica claro pelo documento o comprometimento institucional com o processo, representado pelo departamento FIFA TV, que engloba um largo campo de atuação, dentre o qual a principal fonte de renda da instituição, que é a venda de direitos televisivos. Além disso, o FIFA TV é responsável pela coordenação e gerenciamento da produção de 64 jogos de futebol no espaço de 30 dias e inúmeras horas de conteúdos informativo relativas à 32 seleções participantes, além da prestação de serviços de logística para inúmeras emissoras de televisão que cobrem uma Copa do Mundo. Sejam grandes companhias - que recebem um serviço qualificado e customizado de acordo com as necessidades - ou pequenas emissoras, que já recebem o produto final praticamente pronto, esse documento mostra como a FIFA preza o relacionamento com as emissoras de TV para a construção e difusão do espetáculo esportivo.

A análise dos feeds permite ver que a FIFA tem um bom entendimento sobre as lógicas de funcionamento das emissoras de TV. Além de oferecer serviços complementares, a FIFA disponibiliza, através dos feeds e do FIFA Max, uma grande variedade de conteúdos que vão de encontro às necessidades de emissoras do mundo todo, independente de seu tamanho e presença no país sede. Dessa forma, a FIFA garante que emissoras pequenas possam transmitir os jogos da Copa com um mínimo de qualidade, valorizando o seu produto, e que as emissoras de maior investimento possam acrescentar valor ao produto inicial.

0 investimento em infraestrutura de tecnologias da informação e comunicação escapa da função de origem de uma federação esportiva. Contudo, 
essa transformação pode ser entendida com base na teoria da midiatização. Para Krotz, ${ }^{38}$ a midiatização é uma importante ferramenta para o estudo de cenários em mudança, porque ela atua de maneira transversal, junto com outros metaprocessos da modernidade, como a Globalização, Mercantilização e Digitalização três elementos igualmente importantes na evolução da Copa do Mundo enquanto um produto de TV. Para um evento das dimensões da Copa do Mundo e com pretensões globais, a adoção de lógicas midiáticas é uma condição essencial para sua organização e seu sucesso.

\section{REFERÊNCIAS}

ALTHEIDE, David. Media logic and political communication. Political Communication, v. 21, n. 3, p. 293-296, 2004.

ALTHEIDE, David; SNOW, Robert. Media logic. Hills: Sage, 1979.

BILLINGS, Andrew; WENNER, Lawrence. The curious case of the megasporting event: media, mediatization and seminal sports events. In: WENNER, Lawrence; BILLINGS, Andrew (ed.) Sport, Media and MegaEvents. Londres: Routledge, 2017, p. 3-18.

BORGES, Fernando. O papel da FIFA Fan Fest ${ }^{\mathrm{TM}}$ na copa do mundo da África do Sul. Horizontes Antropológicos, v. 19, n. 40, p. 201-230, 2013.

COULDRY, Nick; HEPP, Andreas. Conceptualizing mediatization: contexts, traditions, arguments. Communication Theory, v. 23, n. 3, p. 191-202, 2013.

FIFA. Who we are. Disponível em: <bit.ly/2Mzbh6H>. Acesso em: 14 ago. 2018.

FIFA. FIFA World Cup TV Production Handbook. Zurique: FIFA, 2018.

FRANDSEN, Kirsten. Sports organizations in a new wave of mediatization. Communication \& Sport, v. 4, n. 4, p. 385-400, 2016.

GRUNEAU, Richard; HORNE, John. Mega-events and globalization: a critical introduction. In: GRUNEAU, Richard; HORNE, John. (ed.) Mega-events and Globalization: capital and spectacle in a changing world order. Londres: Routledge, 2016, p. 1-28.

HAYNES, Richard; BOYLE, Raymond. The FIFA World Cup: media, football and the evolution of the global event. In: WENNER, Lawrence; BILLINGS, Andrew. (ed.) Sport, Media and Mega-events. London: Routledge, 2017, p. 69-99.

${ }^{38}$ KROTZ. The meta-process of "mediatization" as a conceptual frame, p. 256-260. 
HELLAND, Knut. Changing sports, changing media: mass appeal, the sports/media complex and TV sports rights. Nordicom Review, p. 105-119, 2007.

HJARVARD, Stig. The mediatization of society: A theory of the media as agents of social and cultural change. Nordicom Review, v. 29, n. 2, p. 105-134, 2008.

HORNE, John; MANZENREITER, Wolfram. An introduction to the sociology of sports mega-events. The Sociological Review, v. 54, n. 2, p. 1-24, 2006.

HORNE, John; MANZENREITER, Wolfram. Football World Cup finals on the host countries Japan/Korea accounting for mega-events: forecast and actual impacts of the 2002. International Review of Sociology of Sport, v. 39, n. 2, p. 187-203, 2004.

KROTZ, Friedrich. The meta-process of "mediatization" as a conceptual frame. Global Media and Communication, v. 3, n. 3, p. 256-260, 2007.

MARIVOET, Salomé. Euro 2004 ${ }^{\mathrm{TM}}$ : um evento global em Portugal. Lisboa: Livros Horizonte, 2006.

MÜLLER, Martin. What makes an event a mega-event? Definitions and sizes. Leisure Studies, v. 34, n. 6, p. 627-642, 2015.

PAPA, Françoise. Quand le sport nous parle de la télévision. In: GABASTON, Pierre; LECONTE, Bernard (org.) Sports et télévision: regards croisés. Paris: L'Harmattan, 2000, p. 405-425.

ROCHE, Maurice. Mega-events and Modernity: Olympics and Expos in the Growth of Global Culture. Londres: Routledge, 2000.

ROCHE, Maurice. Mega-events, time and modernity: on time structures in global society. Time and Society, v. 12, p. 99-126, 2003.

ROWE, David. Sport, Culture and the Media: the unruly trinity. Berkshire: Open University Press, 2004.

ROWE, David. The global love-match: sport and television. Media, Culture \& Society, v. 18, n. 4, p. 565-582, 1996.

WENNER, Lawrence. Media, sports, and society: The research agenda. In: WENNER, Lawrence. (org.) Media, sports, and society. Newbury Park: Sage, 1989 , p. 13-48.

WHANNEL, Garry. Fields in Vision: Television Sport and Cultural. Transforrmation. Routledge, London, 1992.

WILLE, Fabien. Une diachronie du spectacle sportif télévisé: des logiques d'innovations et de promotions. In: GABASTON, Pierre; LECONTE, Bernard (org.) Sports et télévision: regards croisés. Paris: L'Harmattan, 2000, p. 427-442. 